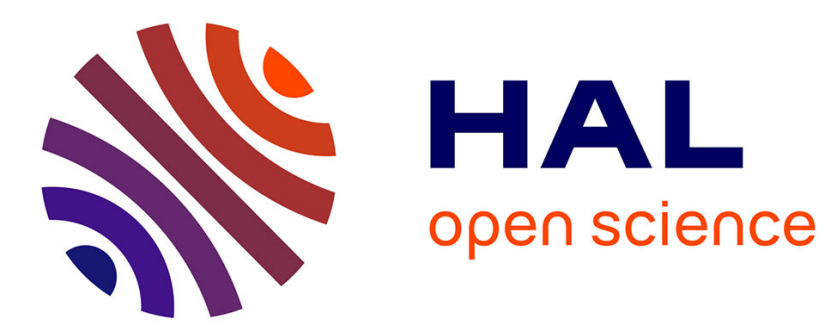

\title{
Modeling of wheat imbibition and germination as influenced by soil physical properties
}

\author{
A. Bouaziz, Laurent Bruckler
}

\section{To cite this version:}

A. Bouaziz, Laurent Bruckler. Modeling of wheat imbibition and germination as influenced by soil physical properties. Soil Science Society of America Journal, 1989, 53 (53), pp.219-227. hal-02724008

\section{HAL Id: hal-02724008 \\ https://hal.inrae.fr/hal-02724008}

Submitted on 2 Jun 2020

HAL is a multi-disciplinary open access archive for the deposit and dissemination of scientific research documents, whether they are published or not. The documents may come from teaching and research institutions in France or abroad, or from public or private research centers.
L'archive ouverte pluridisciplinaire HAL, est destinée au dépôt et à la diffusion de documents scientifiques de niveau recherche, publiés ou non, émanant des établissements d'enseignement et de recherche français ou étrangers, des laboratoires publics ou privés. 
Mineral, 68:1183-1188.

Bohannan, R.G. 1978. Preliminary geologic map of the Las Vegas $1^{\circ} \times 2^{\circ}$ quadrangle, Nevada, Arizona, and California. U.S.G.S. Open-File Report 78-760.

Bradley, W.G:, and J.E. Deacon. 1967. The biotic communities of southern Nevada. p. 201-295. In H.M. Wormington and D. Ellis (ed.) Pleistocene studies in southern Nevada. Nevada State Museum Anthropology Papers 13 :

Braithwaite, C.J.R. 1983. Calcrete and other soils in Quaternary limestones: structures, processes and applications. J. Geol. Soc. (London) 140:351-363.

Folk, R.L. 1974. The natural history of crystalline calcium carbonate: Effect of magnesium content and salinity. Sediment. Petrol. 44:40-53.

Goudie, A.S. 1983. Calcrete. p. 93-131. In A.S. Goudie and K. Pye (ed.) Chemical sediments and geomorphology. Academic Press, London.

Kunze, G.W. 1965. Pretreatment for mineralogical analysis. In C.A. Black (ed.) Methods of soil analysis. Part I. Agronomy 9:568-577. Lahann, R.W. 1978. A chemical model for calcite crystal growth and morphology control. J. Sediment. Petrol. 48:337-344.

Mausbach, M., R. Yeck, D. Nettleton, and W. Lynn. 1982. Principles and procedures for using soil survey calibration data. Natl. Soil Survey Lab. USDA-SCS, Lincoln, NE.

Mermut, A.R., and R.J. St. Arnaud. 1981. A study of microcystalline pedogenic carbonates using microscopic techniques. Can. J. Soil Sci. 61:261-272

National Oceanographic and Atmospheric Administration. 1985. Climatological data, Nevada. National Climatic Data Center, NOAA 100 (13). U.S. Gov. Print. Office, Washington, DC.

Nelson, D.W., and L.E. Sommers. 1982. Total carbon, organic carbon, and organic matter. In A.L. Page (ed.) Methods of soil analysis. Part 2. 2nd ed. Agronomy 9:539-579.

Quade, J. 1986. Late Quaternary environmental changes in the upper Las Vegas Valley, Nevada. Quat. Res. 26:340-357.
Rabenhorst, M.C., and L.P. Wilding. 1984. Rapid method to obtain carbonate-free residues from limestone and petrocalcic materials. Soil Sci. Soc. Am. J. 48:216-219.

Singh, B., and G.S. Sekhon. 1978. Leaching of nitrate in calcareous soils as influenced by its adsorption on calcium carbonate. Geo-
derma 18:271-279.

Sowers, J.M. 1985. Pedogenic calcretes of the Kyle Canyon alluvial fan, southern Nevada: morphology and development. Ph.D. Diss. Univ. of California, Berkeley.

Sowers, J.M. 1986. Geomorphic map of the Kyle Canyon alluvial fan, southern Nevada. U.S. Geological Survey Open-file Report 86-210. U.S. Gov. Print. Office, Washington, DC.

Spaulding, W.G. 1985. Vegetation and climates of the last 45,000 years in the vicinity of the Nevada test site, south-central Nevada. U.S. Geological Survey Professional Paper 1329. U.S. Gov. Print. Office, Washington, DC

St. Amaud, R.J. 1979. Nature and distribution of secondary carbonates within landscapes in relation to soluble $\mathrm{Mg}^{2+} / \mathrm{Ca}^{2+}$ ratios. Can. J. Soil Sci. 59:87-98.

Thornthwaite, C.W. 1948. An approach toward a rational classification of climate. Geogr. Review 38:55-94

Veizer, J. 1983. Trace elements and isotopes in sedimentary carbonates. Chapter 8. In R.J. Reeder (ed.) Carbonates: Mineralogy and chemistry. Reviews in mineralogy, Vol. 11. Mineral. Soc. Am. Book Crafters, Inc., Chelsea, MI.

Watts, N.L. 1980. Quaternary pedogenic calcretes from the Kalahari (southern Africa): Mineralogy, genesis and diagenesis. Sedimentology 27:661-686.

Wieder, M., and D.H. Yaalon. 1974. Effect of matrix composition on carbonate nodule crystallization. Geoderma 11:95-121.

Wieder, M., and D.H. Yaalon. 1982. Micromorphological fabrics and developmental stages of carbonate nodular forms related to soil characteristics. Geoderma 28:203-220.

Winland, H.D. 1969. Stability of calcium carbonate polymorphs in warm, shallow seawater. J. Sediment. Petrol. 39:1579-1587.

\title{
DIVISION S-6-SOIL AND WATER MANAGEMENT AND CONSERVATION
}

\section{Modeling of Wheat Imbibition and Germination as Influenced by Soil Physical Properties}

\author{
A. Bouaziz and L. Bruckler*
}

\section{ABSTRACT}

A theoretical model that was used previously for predicting maize (Zea mays $L_{\text {. }}$ ) seed imbibition, and subsequently, germination, is applied to wheat (Triticum aestivum L.) seeds. The proposed model takes into account the seed-soil water movements in both liquid and rapor phases under nonlimiting aeration conditions. The main varlables that govern the Imbibition process are (i) the seed-soil water potential difference, (ii) the seed contact area as affected by vapor or liquid transfers, and (iii) conductive properties of the seed for both liquid and vapor phases. Laboratory experiments show that (i) the imbibition process occurs both in liquid and vapor phases, (ii) wheat seed must reach a critical moisture content before germination (0.27 $\mathrm{kg} \mathrm{kg}^{-1}$ approximately), and (iii) the rate of the imbibition depeads upon the seed surface area affected by liquid or vapor transfers and on the water potential of the external medium that governs the ability of the seed to reach its critical moisture content. The proposed model is regarded as satisfactory after calibration of the seed conductive properties in liquid and vapor phases. Field experiments involved irrigated and nonirrigated treatments (31.7\% clay,

A. Bouaziz, Inst. Agronomique et Vétêrinaire Hassan II, Dép. d'Agronomie, BP 6202, Rabat, Morocco; and L. Bruckler, Inst. National de la Recherche Agronomique, Station de Science du Sol, BP 91 Domaine St. Paul, 84140 Montfavet, France. Received 18 Feb. 1988. "Corresponding author.

Published in Soil Sci. Soc. Am. J. 53:219-227 (1989).
42.5\% loam, 25.8\% sand) and manual or mechanical sowing. Moisture content, bulk density profiles, and soll porosity analyses were used to estimate the seed-soil contact area. The previous imbibition model was applied to field experiments, combining field data with the laboratory results. This model accurately predicted wheat imbibition and germination. Finally, simulated results compared the effects of climatic conditions and sowing techniques on wheat germination for three climatic sequences. Climate was the major limiting factor illustrating the importance of selecting the suitable sowing techniques to optimize the seed imbibition and germination processes.

SUCCESSFUL GERMINATION process is needed to obtain a good stand. Germination of all seeds at the same time is generally necessary to limit the variability between individual plants after emergence.

Several studies have been recently conducted on the effects of the germination and emergence processes on growth, development and yield in the field (Papy, 1979), and the effects of climatic conditions, soil physical characteristics and sowing techniques on seed germination under more or less dry conditions (Feneck and Papy, 1977; Fleury, 1982; Bouaziz, 1987).

The first stage of the germination process is the im- 
bibition or water uptake of the seed. Thus, our emphasis will be on the imbibition process which governs the ability of the seed to germinate and emerge. It has been shown that (i) for some species a critical seed moisture content must be achieved before the germination process occurs (Hunter and Erickson, 1952; Owen, 1952; Bruckler, 1983a), (ii) seed imbibition is generally dependent upon both soil water potential and seed-soil contact (Hunter and Erickson, 1952; Owen, 1952; Collis-George and Sands, 1959; Sedgley, 1963; Manohar and Heydecker, 1964; Collis-George and Hector, 1966; Hadas, 1969; Hadas, 1970; Hadas and Stibbe, 1973; Hadas and Russo, 1974; Hegarty, 1977; Boiffin et al., 1983; Bruckler, 1983a,b), (iii) soil temperature influences the kinetics of germination and in part the rate of imbibition through the influence of water temperature on its viscosity (Come, 1970; Blacklow, 1972; Boiffin et al., 1983).

Under very wet or nearly saturated soil conditions the oxygen diffusion rate becomes a limiting factor, although the imbibition process occurs at a normal rate (Kaack and Kristensen, 1967; Come, 1970; AlAni et al., 1982).

In the case of maize (Zea mays L.) seeds, a description of the imbibition process under laboratory or field conditions has been proposed, assuming nonlimiting oxygen diffusion rates (Bruckler, 1983a,b; Boiffin et al., 1983).

The purpose of this paper is to test the applicability of such a model to wheat seeds, for predicting the imbibition process and, consequently, the germination rates and kinetics. We will first summarize the imbibition model and then test the proposed approach against laboratory or field experiments with wheat seeds.

\section{THEORY}

\section{Basic Equations for Seed Imbibition}

The model is based upon water transfer from the soil to the seed, and water movements in both liquid and vapor phase are taken into account (Bruckler, 1983a,b). We assume that:

1. The oxygen diffusion rate is a nonlimiting factor.

2. Water transfer occurs from the external medium (subscript e) to the seed (subscript s) through a thin layer with specific water transfer properties in both liquid and vapor phases.

3. The water potential gradients in the soil surrounding the seeds are disregarded: only the mean soil water potential around the seeds and its variation vs. time, if necessary, are considered.

4. the seed and soil water potentials depend on the seed and soil water contents respectively. The two corresponding relationships are assumed to be without hysteresis.

5. Additivity of water flows in liquid and vapor phases from the external medium to the seed is assumed.

Such hypotheses were successfully applied to the imbibition of maize seeds (Bruckler, 1983a,b; Boiffin et al., 1983), and the basic equation of the corresponding model is described as follows

$$
\begin{gathered}
\left(\mathrm{d} \theta_{\mathrm{s}} / \mathrm{d} t\right)=-K^{\prime}\left(\theta_{\mathrm{s}}\right) \cdot\left(S_{\mathrm{l}} / S_{\mathrm{l}}\right) \cdot\left[\Phi_{\mathrm{s}}-\Phi_{\mathrm{e}}\right] \\
-D^{\prime}\left(\theta_{\mathrm{s}}\right) \cdot\left(S_{\mathrm{v}} / S_{\mathrm{t}}\right) \cdot\left[\mathrm{P}_{\mathrm{s}}-\mathrm{P}_{\mathrm{e}}\right]
\end{gathered}
$$

where

$\mathrm{d} \theta_{\mathrm{s}} / \mathrm{d} t=$ rate of increase in seed moisture content (gravimetric basis) per unit time $\mathrm{d} t\left(\mathrm{~kg} \mathrm{~kg}^{-1} \mathrm{~s}^{-1}\right)$;
$K^{\prime}\left(\theta_{3}\right)=$ empirical coefficient which takes into account the variation of conductive properties of the seed vs. its moisture content (liquid phase) $\left(\mathrm{kg} \mathrm{kg}^{-1} \mathrm{~s}^{-1} \mathrm{MPa}^{-1}\right)$;

$D^{\prime}\left(\theta_{\mathrm{s}}\right)=$ empirical coefficient which takes into account the variation of conductive properties of the seed vs. its moisture content (vapor phase) $\left(\mathrm{kg} \mathrm{kg}^{-1} \mathrm{~s}^{-1} \mathrm{MPa}^{-1}\right)$;

$S_{1} / S_{\mathrm{t}} \quad=$ ratio of the seed surface area as affected by water transport in the liquid phase to the total seed surface area;

$S_{\mathrm{v}} / S_{\mathrm{t}} \quad=$ ratio of the seed surface area as affected by water transport in the vapor phase to the total seed surface area;

$\left[\Phi_{\mathrm{s}}-\Phi_{\mathrm{e}}\right]=$ water potential difference between the seed and the external porous medium (liquid phase) (MPa);

$\left[P_{\mathrm{s}}-\mathbf{P}_{\mathrm{e}}\right]=$ vapor pressure difference between the seed and the external porous medium (vapor phase) (MPa).

Thus, the model accounts for the main variables that govern the imbibition process: the model accounts for a relative fraction of the seed surface area affected by the liquid or vapor phase and for the water potential difference between the seed and the external porous medium for each phase. Furthermore, the empirical relationships $\left[K^{\prime}\left(\theta_{\mathrm{s}}\right)\right]$ and $\left[D^{\prime}\left(\theta_{\mathrm{s}}\right)\right]$ have to be calibrated for each seed species, as shown later. It should be noted that the terms $\left(S_{1} / S_{2}\right)$ and $\left(S_{v} / S_{1}\right)$ may vary vs. time when seed-soil contact area changes as shown later. The terms $\left(\Phi_{e}\right)$ and $\left(P_{e}\right)$ may also vary vs. time (due to soil drying or wetting) and this will be taken into account. As a matter of fact, the water potentials in liquid or vapor phases are related using Kelvin's law which gives

$$
\Phi=(R T / M g) \cdot \ln \left[H_{\mathrm{r}}\right]
$$

where $R, T, M, g, H_{\mathrm{r}}$ are the ideal gas constant, absolute temperature, water molar mass, acceleration due to gravity, and relative humidity, respectively.

As indicated above, the effect of the temperature on the water viscosity and thus, the on the $K^{\prime}\left(\theta_{s}\right)$ coefficient, is taken into account as follows

$$
K_{2}^{\prime}\left(\theta_{\mathrm{s}}\right)=\left[\mu_{1} / \mu_{2}\right] \cdot K_{1}^{\prime}\left(\theta_{\mathrm{s}}\right)
$$

where $\mu_{i}$ represents the water viscosity in $\mathrm{kg} \mathrm{s}^{-1} \mathrm{~m}^{-1}$ at the temperatures $T_{\mathrm{i}}$.

\section{Seed-Soil Contact}

While precise measurements of the terms $S_{1}$ and $S_{\mathrm{v}}$ can be made under controlled laboratory conditions, it is impossible to provide experimental data for these variables under field conditions. Furthermore, it is obvious that the seed-soil contact depends upon the soil structure, aggregate size and soil water content. If we have a wet soil at a given bulk density, the contact between seeds and aggregates will determine whether a given area of the seed surface is in contact with water in the liquid or the vapor phase. If the same soil becomes drier, or even completely dry, the liquid contact may disappear. For this reason, we will distinguish the two following cases:

\section{Case 1}

The soil water potential around the seed is nonlimiting (wet soil). This occurs when the soil water potential is very high compared with the seed water potential, as shown later. In this case, the empirical relationship between the seed surface area affected by liquid transfers and the soil structure was described from maize seeds in contact with small regular (2-3 mm) aggregates (Bruckler, 1983b)

$$
S_{\mathrm{l}} / S_{\mathrm{t}}=0.94 \cdot\left(1-n_{\mathrm{s}}\right)-0.16
$$

where: $n_{\mathrm{s}}=$ air filled structural porosity, and $S_{\mathfrak{l}}=$ total seed 
surface area. Thus, for wet conditions, we will test in this paper the ability of such an empirical relationship to be successfully applied to wheat seeds under field conditions.

Case 2 The soil water potential around the seed is limiting (dry soil). In this case, the seed-soil surface contact (liquid phase) decreases as the soil water potential decreases. An example is given in Fig. 1 and the corresponding Eq. [5] for maize seeds (Bruckler, 1983b)

$$
S_{1} / S_{\mathrm{i}}=(0.38) \cdot \exp \left[-0.55 \cdot\left|\Phi_{\mathrm{e}}\right|\right]
$$

(assuming a dry bulk density equal to $0.9 \mathrm{Mg} \mathrm{m}^{-3}$.)

Equation [5] was provided for a soil layer composed of regular small aggregates with a dry bulk density of 0.9 $\mathrm{Mg}^{\prime} \mathrm{m}^{-3}$. Thus, for dry soils, our objective is to test the ability of such a decreasing relationship to provide a comprebensive approach to the wheat seed-soil contact. If the actual dry bulk density is equal to $0.9 \mathrm{Mg} \mathrm{m}^{-3}$, the relationship given in Fig. 1 can be applied directly. If not, and if the ctual soil bulk density is greater than $0.9 \mathrm{Mg} \mathrm{m}^{-3}$, the calculated value given by Eq. [5] will be multiplied by the ratio of the actual bulk density to the reference bulk density $(0.9$ $\mathrm{N}\left(\mathrm{m}^{-3}\right)$ to account for the soil compaction effects.

\section{MATERIALS AND METHODS}

\section{Laboratory Experiments}

Laboratory experiments were conducted in order to (i) eximate the critical seed water content allowing the germination process to occur, (ii) obtain experimental estiantes for the soil retention curve $\left[\Phi\left(\theta_{c}\right)\right]$ and seed retention rurve $\left[\Phi\left(\theta_{s}\right)\right]$, (iii) provide consistent estimates for the mean water transfer characteristics for both liquid and vapor pheses $\left[K^{\prime}\left(\theta_{s}\right)\right.$ and $D^{\prime}\left(\theta_{3}\right)$, respectively] and, (iv) test the gencol model given by Eq. [1]. The hypothesized sum of vapor and liquid water flows from the external porous medium to teed during imbibition, and the effects of the water poential and/or the seed soil contact will be studied.

Moroccan wheat seeds ('NESMA 149') were used for both boratory and field experiments. The search for the critical ater content was conducted using imbibition experiments. A very low water potentials $(<-3.5 \mathrm{MPa})$, the experiments we carried out using vapor equilibrium. The seeds were theed in the vapor phase over different solution concentratoos in a thermal bath for 2 or $3 \mathrm{wk}$ and seed water content sensurements and germination observations vs. time were At higher external water potential $(>-3.4 \mathrm{MPa})$, difneat polyethylene glycol (PEG 6000) concentrations were ing thing into account the empirical concentration-water wetial relationship given by Michel and Kaufmann (1973). woording to these experiments, the same data sets (seed wer contents and seed water potentials) were used for esbeting the $\left[\Phi_{s}\left(\theta_{s}\right)\right]$ relationship for wheat seeds before gerintion.

Separate imbibition experiments ( 0 and $-3.4 \mathrm{MPa}$ ) were wormed for the liquid phase only (the seeds were covered thin layer of water or PEG solution), the vapor phase 4 (seeds were placed in a closed gaseous phase over free 4. -3.4 MPA PEG solution) and, combined liquid a vor phases (one half of the seed was located in satad sand, and the other half was in contact with the vapo c). Experiments in liquid or vapor phases were carried to estimate the $\left[K^{\prime}\left(\theta_{s}\right)\right]$ or $\left[D^{\prime}\left(\theta_{s}\right)\right]$ coefficients separately. imenents combining liquid and vapor flows were used the additivity of the liquid and vapor water fluxes ine the imbibition process.

\section{Field Experiments}

Fied experiments were carried out under Moroccan ag-hurl conditions using irrigated or nonirrigated plots and or mechanical sowing. Manual sowing, which is the

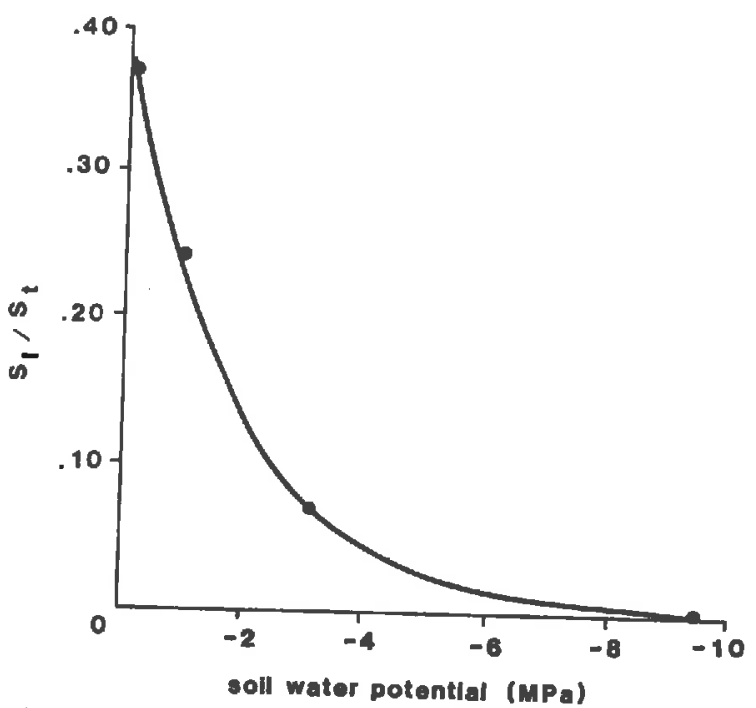

Fig. 1. Relationship between the ratio of the seed surface affected by liquid phase to the total seed surface, and the soil water potential (aggregates 2-3 mm, maize seeds; after Bruckler, 1983b)

main traditional sowing practice, generally produced an extremely variable seeding depth, whereas mechanical sowing

The soil water content-water potential relationship was measured in the laboratory using a pressure plate apparatus. Furthermore, the shrinking curve of the soil (31.7\% clay, $42.5 \%$ loam, $25.8 \%$ sand) was estimated to obtain a precise description of the structural changes vs. time under field conditions according to the shrinking effects (Stengel, 1979; Fies and Stengel, 1981).

For each treatment, four replicates were performed. The main field controls provided (i) dry bulk density measurements (measurements at five different times, four replicates for each time), (ii) gravimetric water content measurements (measurements at five different times, four replicates at each time). The bulk density data were collected for $50-\mathrm{mm}$ thick soil layers using the core sampling technique from 0 to 0.2 $\mathrm{m}$, whereas the gravimetric water content measurements were performed for $20-\mathrm{mm}$ deep soil layers from 0 to $0.1 \mathrm{~m}$, and for $50-\mathrm{mm}$ deep soil layers from 0.10 to $0.20 \mathrm{~m}$. The and mination rates were observed at five different times, and eight replicates were recorded for each time. Air-filled structural porosity and void ratios were estimated from bulk density, water content and shrinking curve values. Furthermore, precise seed positions in the seed beds were observed for each treatment. As a result of $16-\mathrm{mm}$ rainfall just after sowing, the irrigated and nonirrigated plots had the same moisture content at the beginning of the imbibition process. Additional irrigation was applied to the irrigated plots $8 \mathrm{~d}$ after sowing.

\section{RESULTS}

\section{Laboratory Experiments}

\section{Basic Soil Properties}

Figure 2 shows the water content-water potential relationship at a soil water potential ranging from 0 to $-1.6 \mathrm{MPa}$, whereas Fig. 3 gives the estimated soil shrinking curve. For gravimetric water contents less than approximately $0.10 \mathrm{~kg} \mathrm{~kg}^{-1}$, soil shrinking phenomena disappear and the soil matrix is regarded as rigid. The experimental data given in Fig. 2 and 3 and the corresponding curves were used for the field im- 


\section{Basic Seed Properties}

Figure 4 gives the experimental seed water contentwater potential relationship collected from vapor phase equilibrium experiments. Note that before experiments, all the seeds were stored in a dry vapor phase at constant water potential (approx. $-100 \mathrm{MPa}$ ). The corresponding seed water content was arbitrarily noted "0 moisture content" or "conservation moisture" in Fig. 4. Thus, when the water potential of the vapor phase was below $-100 \mathrm{MPa}$, seeds were able to release water, thus giving a negative seed moisture content compared to the seed conservation moisture content.

Table 1 indicates the experimental relationship between seed water content, seed water potential and germination rates for a small range of the water potential of the external medium (liquid phase, different PEG concentration). Germination did not occur at 80

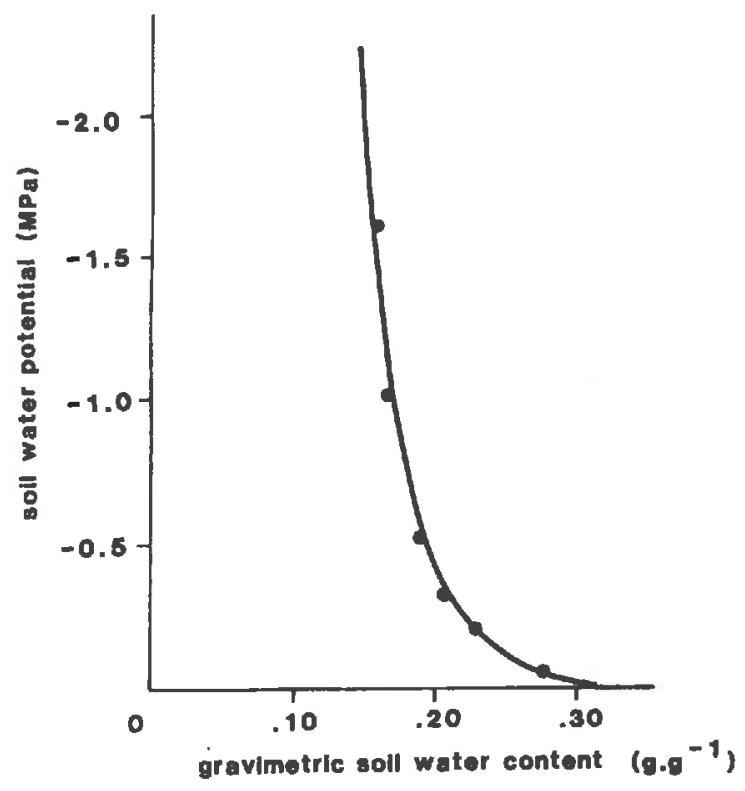

Fig. 2. Soil water content/water potential relationship.

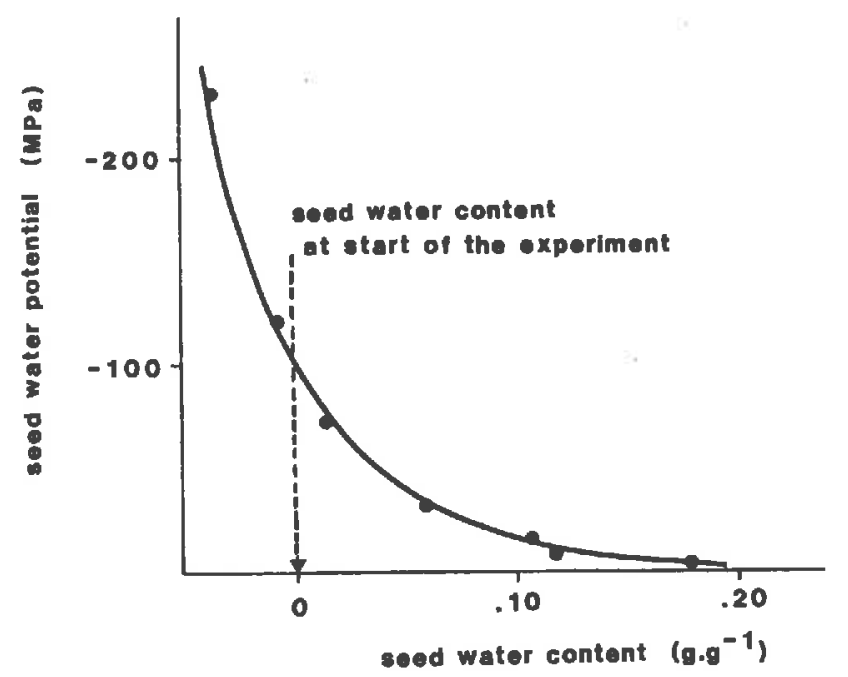

Fig. 4. Wheat seed water content/water potential relationship (the 0 seed moisture content corresponds to the initial seed moisture content at start of the experiment, when seeds were stored at a constant $-100 \mathrm{MPa}$ water potential). $\mathrm{h}$ at a water potential below $-2.9 \mathrm{MPa}$, while it occurred at water potentials above $-2.9 \mathrm{MPa}$. Thus, the corresponding critical seed water content for germination was approximately $0.27 \mathrm{~kg} \mathrm{~kg}^{-1}$ (Table 1 ).

Figure 5 shows experimental seed imbibition curves obtained from vapor phase imbibition experiments using contrasted external water potential values $(0$, $-3.4,-7.4,-30 \mathrm{MPa})$. At a zero potential value, the imbibition process is rapid and regular until germination occurs. The same results were observed up to $-0.9 \mathrm{MPa}$, imbibition curves and imbibition duration before germination were the same. Thus, the $[0$, $-0.9 \mathrm{MPa}$ ] soil water potential range will be called the nonlimiting domain. This result agrees with those of Lindstrom et al., 1976. Below $-0.9 \mathrm{MPa}$ and above approximately $-3 \mathrm{MPa}$, germination occurred, but at a lesser rate compared with the nonlimiting domain. Below approximately $-3 \mathrm{MPa}$, the imbibition process occurred until a constant seed water content was achieved, which remained constant if the external water potential remained constant. Thus, at such soil water potential, germination was impossible because of the limiting imbibition process. The same results were obtained for the liquid phase imbibition experiments: As an example, Figure 6 shows an approach to equilibrium at constant seed water content for the

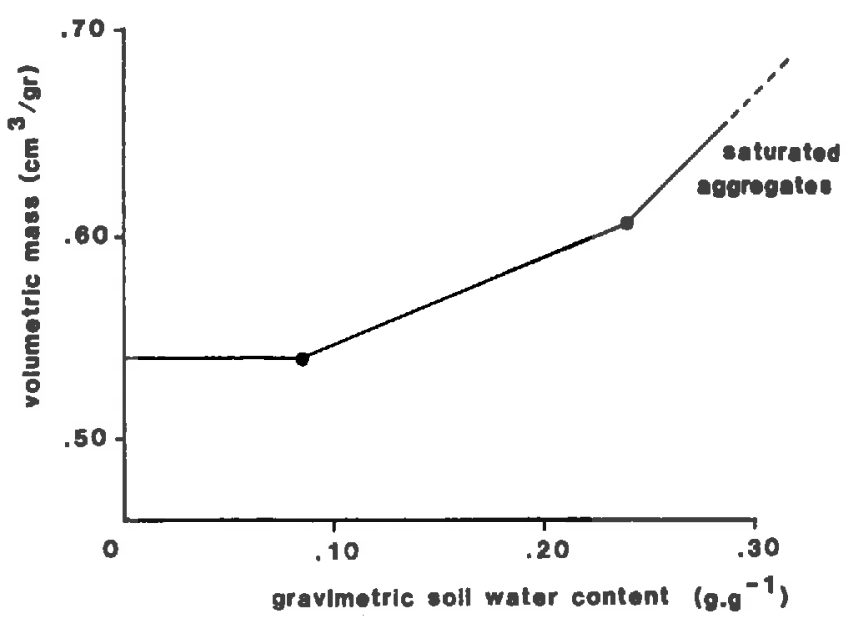

Fig. 3. Estimated soil shrinking curve.

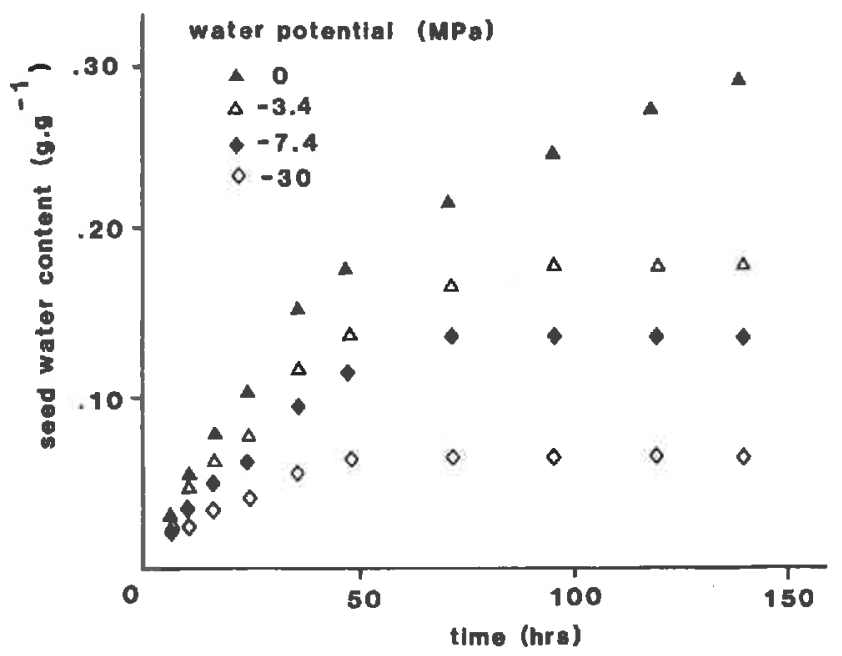

Fig. 5. Wheat seed imbibition in vapor phase at different water potentials. 
$-3.4 \mathrm{MPa}$ external water potential. Note that these experimental results agree with the basic imbibition model (Eq. [1]), because the seed water content variation vs. time is theoretically equal to 0 when the seedsoil water potential difference is equal to 0 for the vapor and/or liquid phases.

Figure 7 and 8 show the liquid/vapor seed surface effects on imbibition rate at a 0 or $-3.4 \mathrm{MPa}$ water potential, respectively. The imbibition kinetics depend highly on the relative parts of the seed affected by liquid and vapor phases, respectively. Figure 8 shows that the seed surface affected by liquid or vapor water movements determines the kinetics of imbibition but does not change the maximum seed water content which depends only on the seed-soil water potential difference as indicated by Eq. [1].

\section{Seed Parameters Estimation}

The proposed scheme as given by Eq. [1] is useful for the imbibition model only if the basic coefficients $K^{\prime}\left(\theta_{\mathrm{s}}\right)$ and $D^{\prime}\left(\theta_{\mathrm{s}}\right)$ are known. According to the laboratory experimental data, the $K^{\prime}\left(\theta_{\mathrm{s}}\right)$ and $D^{\prime}\left(\theta_{\mathrm{s}}\right)$ relationships were fitted for the liquid and vapor phases, respectively.

Liquid Phase. Laboratory experiments where seeds were placed in pure water ( 0 potential) were used. Subsequently, these experimental conditions implied

$$
\left(S_{\mathrm{v}} / S_{\mathrm{l}}\right)=0,\left(S_{\mathrm{l}} / S_{\mathrm{l}}\right)=1, \Phi_{\mathrm{e}}=0 .
$$

Table 1. Experimental relationship between the wheat germination rate and the seed water content as affected by external water porential.

\begin{tabular}{cccc}
\hline $\begin{array}{c}\text { External water } \\
\text { potential }\end{array}$ & $\begin{array}{c}\text { Seed water } \\
\text { content }\end{array}$ & $\begin{array}{c}\text { Number of } \\
\text { germinated seeds } \dagger\end{array}$ & $\begin{array}{c}\text { Time for } \\
\text { germination }\end{array}$ \\
\hline (MPa) & $\mathbf{k g ~ k g}^{-1}$ & & $(\mathrm{~h})$ \\
0 & 0.289 & 10 & 56 \\
-2.9 & 0.265 & 9 & 68 \\
-3.0 & 0.240 & 5 & 68 \\
-3.1 & 0.185 & 2 & 80 \\
-3.2 & 0.178 & 0 & $\ddagger$ \\
-3.3 & 0.176 & 0 & $\ddagger$ \\
-3.4 & 0.175 & 0 & $\ddagger$ \\
\hline
\end{tabular}

$\dagger$ Total number of seeds: 10 .

$\ddagger$ Observation at time $=80 \mathrm{~h}$.

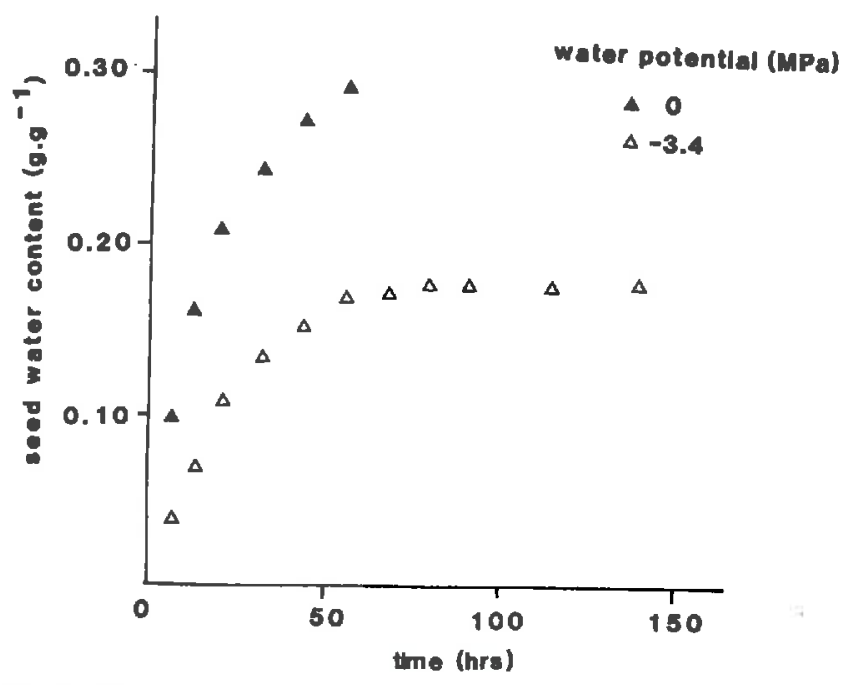

Fig. 6. Wheat seed imbibition in liquid phase at different water potentials.
Thus, Eq. [1] reduced here to

$$
\left(\mathrm{d} \theta_{\mathrm{s}} / \mathrm{d} t\right)=-K^{\prime}\left(\theta_{\mathrm{s}}\right) \cdot \Phi_{\mathrm{s}}\left(\theta_{\mathrm{s}}\right) .
$$

Vapor Phase. Using laboratory experiments where seeds were placed in a saturated vapor phase, it came

$$
\begin{gathered}
\left(S_{\mathrm{v}} / S_{\mathrm{t}}\right)=1,\left(S_{\mathrm{l}} / S_{\mathrm{t}}\right)=0, \mathrm{P}_{\mathrm{c}}=0, \text { and then } \\
\left(\mathrm{d} \theta_{\mathrm{s}} / \mathrm{d} t\right)=-D^{\prime}\left(\theta_{\mathrm{s}}\right) \cdot \mathrm{P}_{\mathrm{s}}\left(\theta_{\mathrm{s}}\right) .
\end{gathered}
$$

Thus, the two seed parameters $\left[K^{\prime}\left(\theta_{s}\right)\right]$ and $\left[D^{\prime}\left(\theta_{s}\right)\right]$ could be independently estimated using Eq. [6] or [7].

This was done by solving numerically Eq. [6] and [7] using a simple finite difference calculation scheme with a constant time step of 360 s. Seed water content $\left(\theta_{s}\right)$ was assumed to be 0 at the start of the calculations, and the seed water content-seed water potential relationship (see Fig. 4) was used for seed water potential calculations at each time step. After different computer runs, the same relevant analytical relationship was chosen for the $K^{\prime}\left(\theta_{\mathrm{s}}\right)$ and $D^{\prime}\left(\theta_{\mathrm{s}}\right)$ coefficients as follows

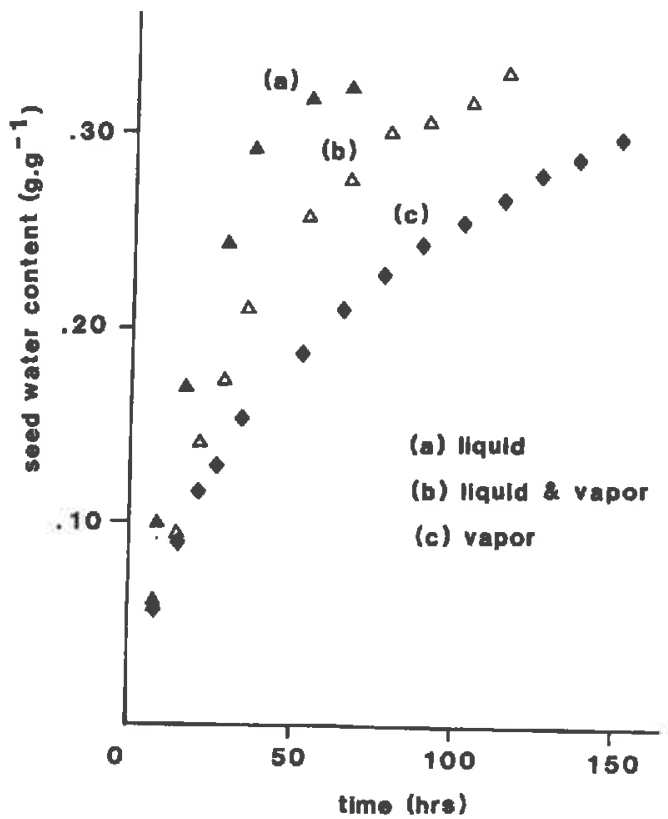

Fig. 7. Wheat seed imbibition in liquid, vapor or combined phases (0 water potential).

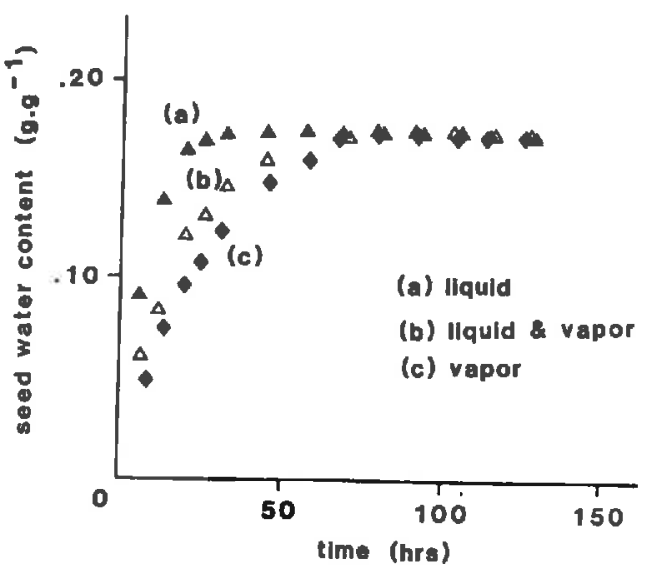

Fig. 8. Wheat seed imbibition in liquid, vapor, or combined phases (- 3.4. MPa water potential). 


$$
\begin{gathered}
K^{\prime}\left(\theta_{\mathrm{s}}\right)=\mathrm{c}_{11} \cdot \exp \left[\mathrm{c}_{21} \theta_{\mathrm{s}}\right] \\
D^{\prime}\left(\theta_{\mathrm{s}}\right)=c_{1 \mathrm{v}} \cdot \exp \left[\mathrm{c}_{2 \mathrm{v}} \theta_{\mathrm{s}}\right] .
\end{gathered}
$$

Empirical constants $\left[c_{11}, c_{21}\right]$ and $\left[c_{1 v}, c_{2 v}\right]$ were estimated using a mean square nonlinear fitting procedure (Bard, 1974) to minimize the residuals between observed and calculated seed moisture contents $\left(\theta_{\mathrm{s}}\right)$. The estimated parameters are listed in Table 2. As a matter of fact, the seed parameter $\left(c_{11}\right)$-liquid phasewas logically greater than the seed parameter $\left(c_{1 v}\right)-$ vapor phase. These estimated parameters will be used for all other computations in the text.

Figures 9 and 10 show the observed and calculated

Table 2. Estimated seed parameters for the liquid and vapor phase (Eq. [8] and [9]).

\begin{tabular}{ccc}
\hline \multicolumn{3}{c}{ Liquid phase } \\
\hline Seed parameters & Mean & Confidence interval \\
\hline$c_{11} \dagger$ & $8.03 \times 10^{-1}$ & {$\left[6.89 \times 10^{-8} ; 9.14 \times 10^{-8}\right]$} \\
$c_{21}$ & 9.79 & {$[8.93 ; 10.66]$} \\
\hline \multicolumn{4}{c}{ Vapor phase } \\
\hline Seed parameters & Mean & Confidence interval \\
\hline$c_{1 v} \dagger$ & $1.86 \times 10^{-8}$ & {$\left[1.70 \times 10^{-8} ; 2.01 \times 10^{-8}\right]$} \\
$c_{2 v}$ & $12.30^{-8}$ & {$[11.73 ; 12.87]$} \\
\hline
\end{tabular}

$\dagger\left(\mathrm{kg} \mathrm{kg}^{-1} \mathrm{~s}^{-1} \mathrm{MPa}^{-1}\right)$.
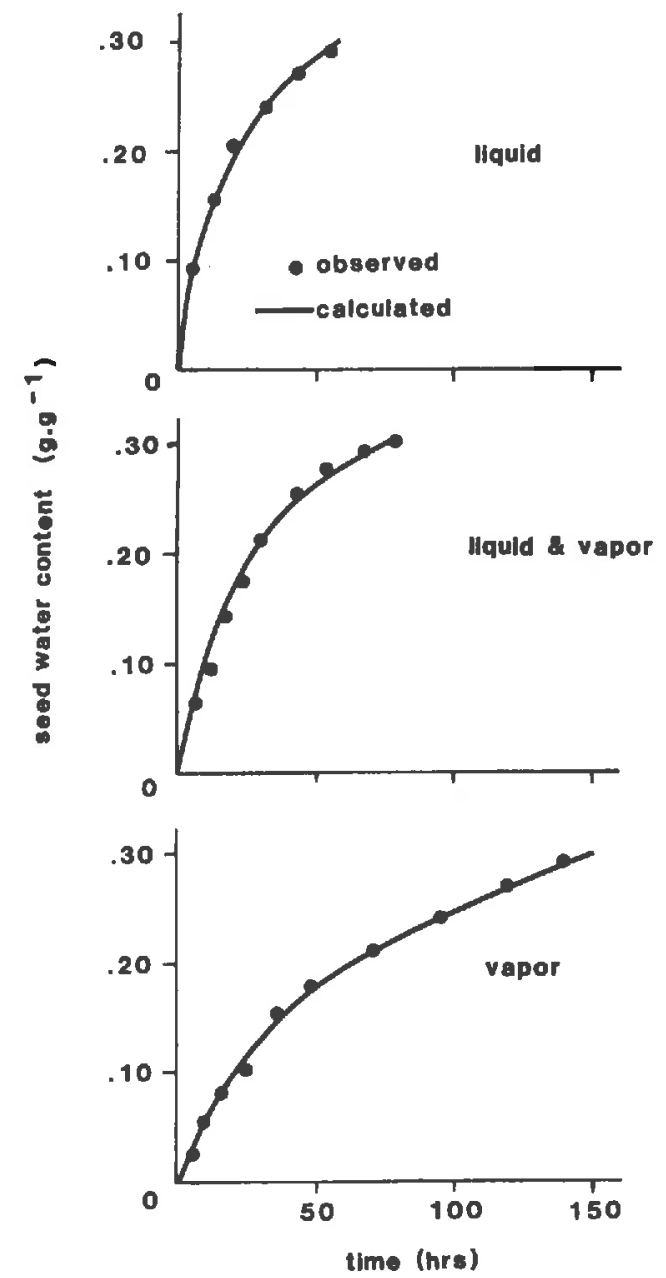

Fig. 9. Measured and calculated wheat seed imbibition for liquid, vapor or combined phases ( 0 water potential). imbibition curves for two water potential levels ( 0 ce $-3.4 \mathrm{MPa})$ and using liquid $\left(S_{1} / S_{1}=1, S_{\mathrm{v}} / S_{1}=\right.$ vapor $\left(S_{1} / S_{\mathrm{t}}=0, S_{\mathrm{v}} / S_{\mathrm{t}}=1\right)$ or combined ( $S / \mathrm{S}_{\mathrm{g}}$ $\left.0.5, S_{\mathrm{v}} / S_{\mathrm{t}}=0.5\right)$ phases for water transfers. Re indicate that the $K^{\prime}\left(\theta_{s}\right)$ and $D^{\prime}\left(\theta_{s}\right)$ estimates provits satisfactory numerical imbibition model. Furtive more, the sum of the water fluxes in liquid and $n$ phases is the relevant value. Thus, the theoret. model of imbibition of wheat seeds as given by [1] is acceptable, provided that preliminary extiment of the $K^{\prime}\left(\hat{\theta}_{\mathrm{s}}\right)$ and $D^{\prime}\left(\theta_{\mathrm{s}}\right)$ relationships are known.

Thus, the main properties of the imbibition and mination processes for wheat seeds are (i) The inti bition process occurs in liquid and/or vapor phom (ii) The external water potential effects on seed in bibition and germination are negligible from 0 to -0.9 $\mathrm{MPa}$ (nonlimiting water range). (iii) Germination curs from 0 to approximately $-3 \mathrm{MPa}$ (and therefor the critical seed water content is approximately oqu to $0.27 \mathrm{~kg} \mathrm{~kg}^{-1}$ ), whereas the imbibition curves show a maximum water content for external water potertials below $-3 \mathrm{MPa}$. (iv) The surfaces affected by liq. uid or vapor transfers do not alter the possibility of germination and/or the maximum seed water content they only affect the imbibition rate. (v) This makes it possible to estimate seed properties for water transfers in liquid and vapor phases (Eq. [8] and [9]). (vi) The
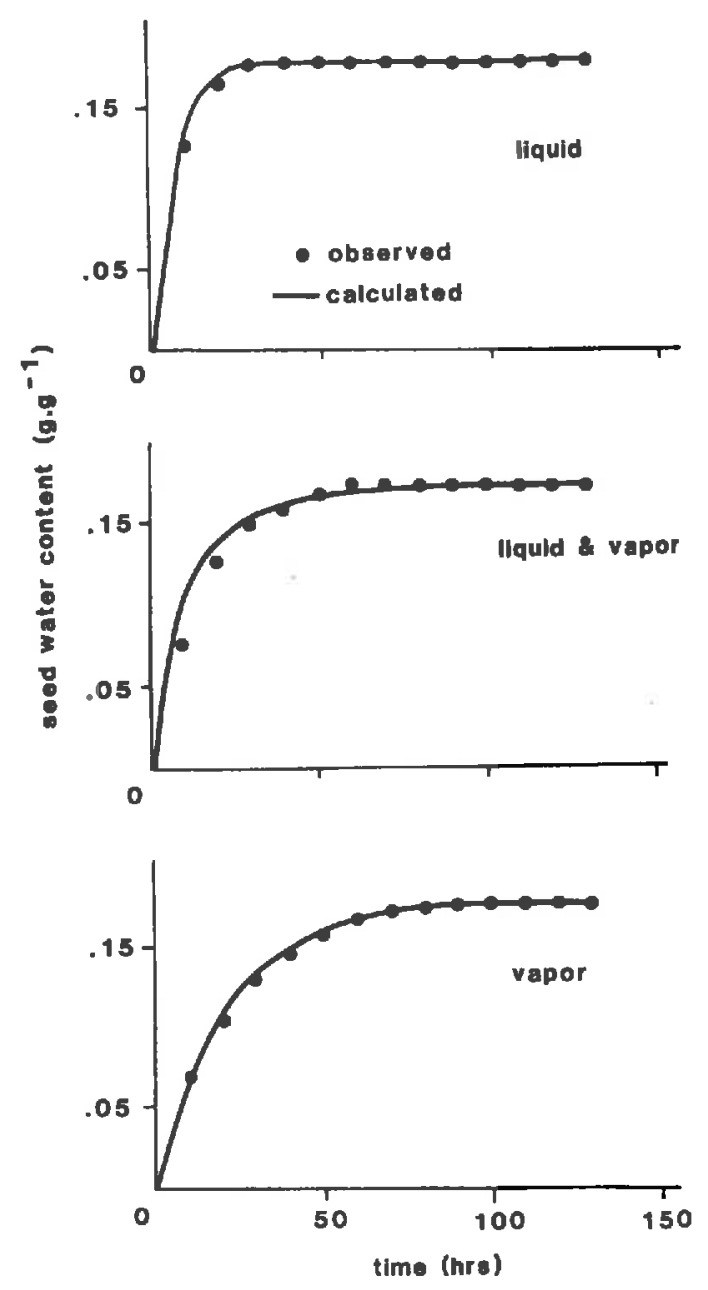

Fig. 10. Measured and calculated wheat seed imbibiton for liquid, vapor or combined phases (-3.4 $\mathrm{MPa}$ water potential). 

theoretical seed imbibition model given by Eq. (1) ap-
plies to wheat seeds.

\section{Field Experiments and Modeling}

Experiments were carried out to test the proposed imbibition model under field conditions. The basic equations are given by Eq. [1], [4], [5], [8], [9], but other variables are needed to estimate some characteristics of the imbibition process. Table 3 summarizes the input files used for the imbibition process under field conditions The main steps of the numerical procedure are: (i) The water transfer coefficients $K^{\prime}\left(\theta_{\mathrm{s}}\right)$ and $D^{\prime}\left(\theta_{\mathrm{s}}\right)$ were those estimated under laboratory conditions. The mean daily temperature was used to incorporate the effect of temperature on the water viscosity in Eq. [3]. (ii) The soil and seed water content-water potential relationships were those measured in the preliminary laboratory experiments. (iii) According to laboratory measurements, the critical seed water content and water potential were unchanged. (iv) The seed surface area affected by liquid and/or vapor water movements was calculated from Eq. [4] and [5], after preliminary testing of the limiting or nonlimiting soil water potential. Estimates of the air-filled structural porosity were calculated at each time step from the water content profiles, bulk density, solid particle density measurements and soil shrinking curve. The bulk density profiles were as-

Table 3. Soil, climate, seeds and sowing characteristics for field imbibition and germination modeling.

\begin{tabular}{ll}
\hline Characteristics & Description \\
\hline Soil & Shrinking curve \\
& Solid particle density \\
& Water content-water potential relationship \\
& Water content profiles vs. time \\
& Soil bulk density profiles \\
& Dates of rainfall \\
Climate & Daily minimal and maximal air temperature \\
Seeds and sowing & Seed positions in the seedbed \\
& Seed crit surface properties \\
& Seed water content/water patential \\
& relationship \\
& Transfer coefficients in liquid and vapor \\
& phases \\
\hline
\end{tabular}

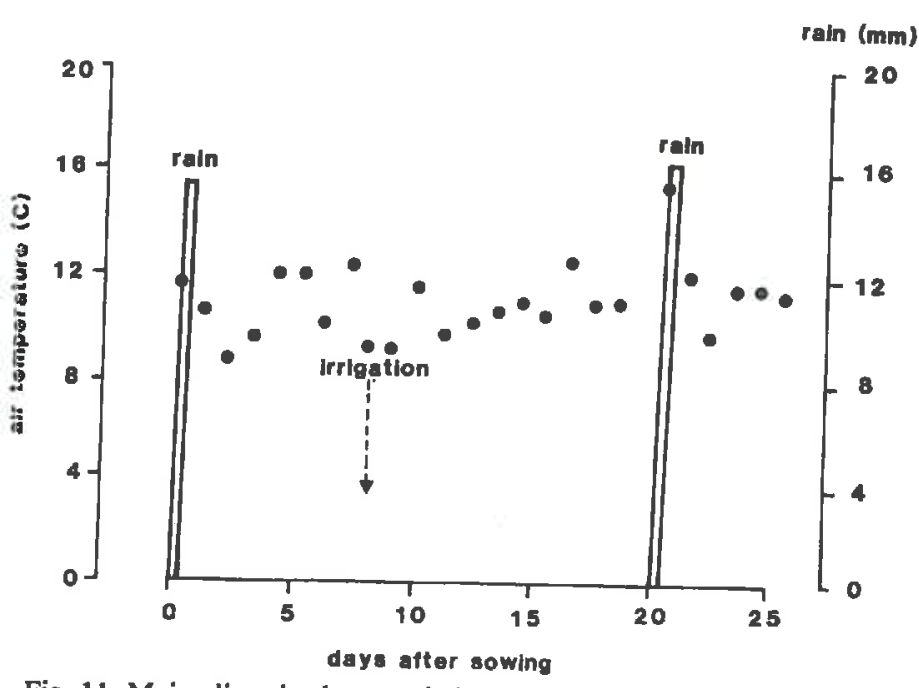

Fig. 11. Main climatic characteristics during the field experiments. sumed to be constant during the imbibition. The soil water content at any time between the dates $i$ and $i$ +1 -and subsequently, the soil water potential-when experimental water content profiles were known, was calculated using a linear interpolation between the dates $i$ and $i+1$. Any rainfall or irrigation occurring between the times $i$ and $i+1$ was taken into account, assuming that the soil water content between the rainfall and time $i+1$ was equal to the observed water content at time $i+1$. (v) The observed positions of the seeds in the seed bed were used to apply Eq. [1] for each 10-mm soil layer from the soil surface to the maximum observed sowing depth.

Figure 11 shows the general climatic conditions during the field experiments for both the irrigated and nonirrigated plots, and Fig. 12 the mean water content profiles for the irrigated and nonirrigated treatments.

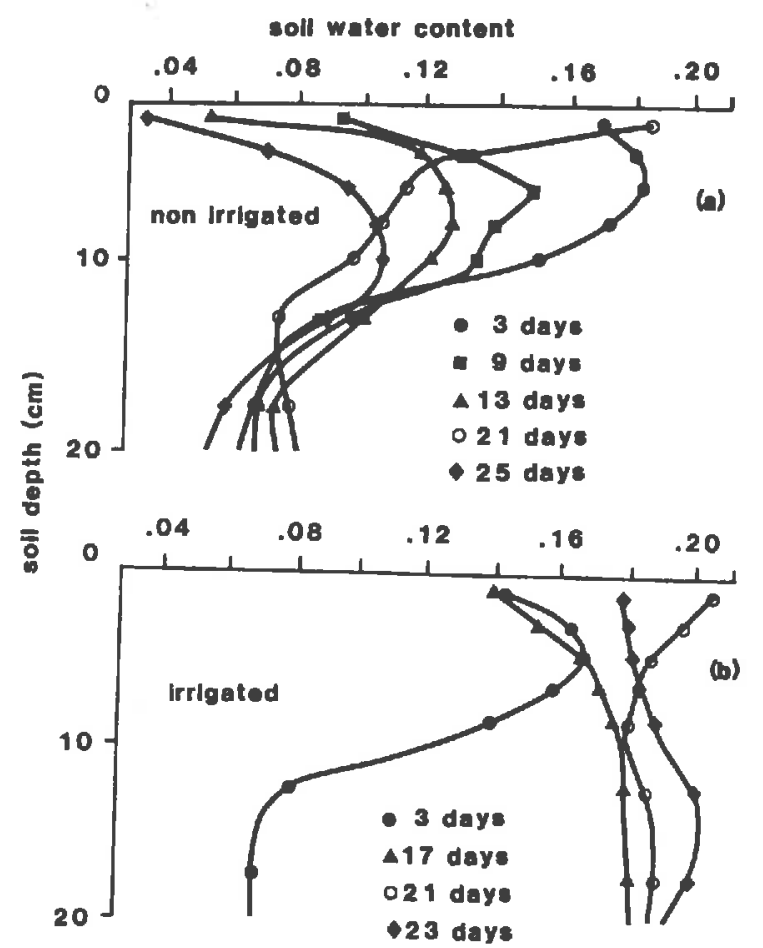

Fig. 12. Water content profiles for the irrigated and nonirrigated plots during the field experiments.

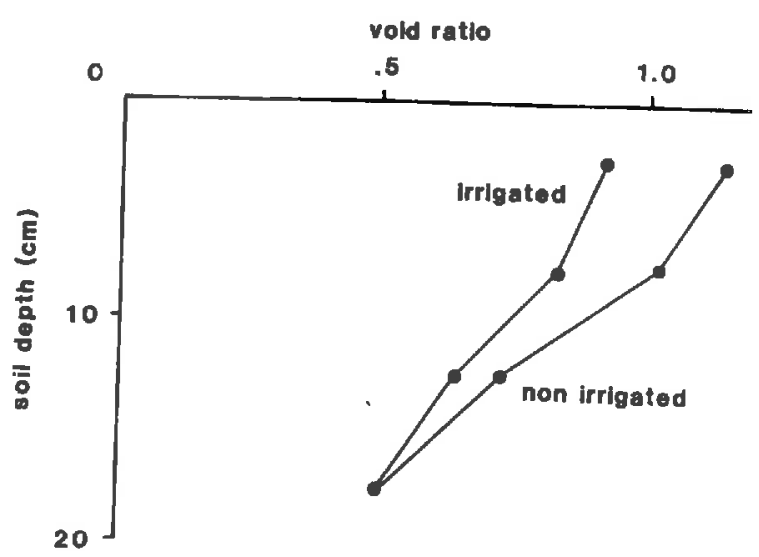
Fig. 13. Structural void ratios for the irrigated and nonirrigated plots
during the field experiments. 


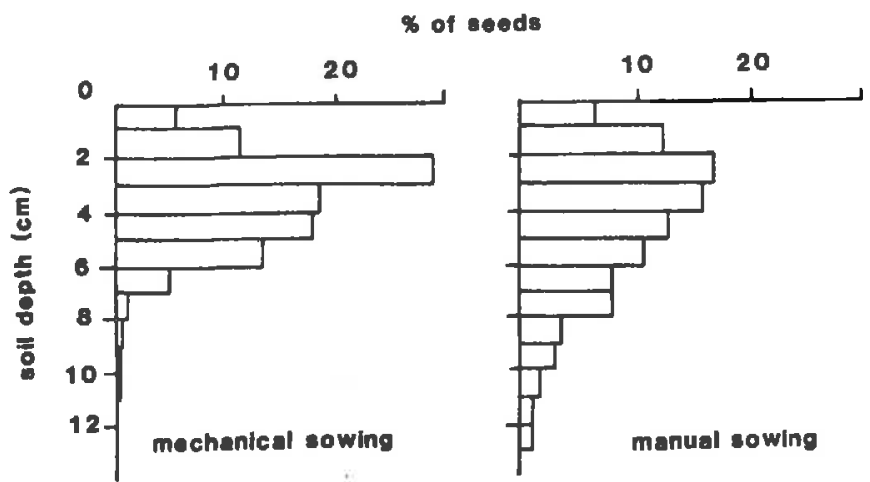

Fig. 14. Frequency distributions of the wheat seeds in the seedbed using mechanical or manual sowing techniques.

Due to rainfall upon sowing, the soil moisture content was relatively high and equal for all treatments. For the nonirrigated plots, the soil surface layers became very dry until $21 \mathrm{~d}$ after sowing, whereas the soil water content remained high in the top soil layers for the irrigated plots (irrigation $8 \mathrm{~d}$ after sowing). Fig. 13 compares the soil structure of the irrigated and nonirrigated plots on a void ratio basis. Some slight differences appearing between the two treatments were taken into account in the seed-soil contact estimation and the imbibition numerical modeling. Finally, Fig. 14 gives the observed positions of the seeds vs. soil depth for mechanical and manual sowing. Note that manual sowing induced a large variation in depth of seed placement until $0.13 \mathrm{~m}$, whereas the seeds were located in the upper soil layers after mechanical sowing.

Results of the numerical model compared with experimental observations are given in Table 4 and Fig. 15. Table 4 indicates that the beginning, the end and the total rates of germination were generally satisfactorily estimated. No differences between irrigated and nonirrigated plots were observed or calculated for the beginning of the germination process, because the soil layers were wet for all plots. The duration of germination differed between the irrigated (10.5 d) and the nonirrigated treatments (23.5 d), however. Resumption of the germination process was observed after 8 $\mathrm{d}$ and calculated after $8.8 \mathrm{~d}$ for the irrigated plots (irrigation effect). For the nonirrigated treatments, resumption of germination was observed after $21 \mathrm{~d}$ and calculated after $22 \mathrm{~d}$ (rainfall effects). Figure 15 shows the observed and predicted germination curves for the

Table 4. Comparison between measured and calculated germination characteristics for the field experiments.

\begin{tabular}{|c|c|c|c|c|c|}
\hline \multirow[b]{2}{*}{ Germination } & & \multicolumn{2}{|c|}{ Imigated } & \multicolumn{2}{|c|}{ Nonirrigated } \\
\hline & & $\begin{array}{c}\text { Mechanical } \\
\text { sowing }\end{array}$ & $\begin{array}{c}\text { Manual } \\
\text { sowing }\end{array}$ & $\begin{array}{l}\text { Mechanical } \\
\text { sowing }\end{array}$ & $\begin{array}{l}\text { Manual } \\
\text { sowing }\end{array}$ \\
\hline Start & $\begin{array}{l}\text { Observed: } \\
\text { Calculated: }\end{array}$ & & & & $\begin{array}{l}d \\
d\end{array}$ \\
\hline End & $\begin{array}{l}\text { Obs: } \\
\text { Cal: }\end{array}$ & $\begin{array}{r}10.5 \\
9.8\end{array}$ & & $\begin{array}{l}23.5 \\
22.0\end{array}$ & d \\
\hline Comments & $\begin{array}{l}\text { Obs: } \\
\text { Cal: }\end{array}$ & $\begin{array}{l}\text { Resumption } \\
\text { germination } \\
\text { Resumption } \\
\text { germination }\end{array}$ & $\begin{array}{l}\text { of } \\
\text { at } 8 \mathrm{~d} \\
\text { of } \\
\text { at } 8.8 \mathrm{~d}\end{array}$ & $\begin{array}{l}\text { Resumption } \\
\text { germination } \\
\text { Resumption } \\
\text { germination }\end{array}$ & $\begin{array}{l}\text { of } \\
\text { at } 21 \mathrm{~d} \\
\text { of } \\
\text { at } 22 \mathrm{~d}\end{array}$ \\
\hline Rate & $\begin{array}{l}\text { Obs: } \\
\text { Cal: }\end{array}$ & $\begin{array}{r}99 \% \\
100 \%\end{array}$ & $\begin{array}{r}99 \% \\
100 \%\end{array}$ & $\begin{array}{l}99 \% \\
99 \%\end{array}$ & $\begin{array}{l}98 \% \\
91 \%\end{array}$ \\
\hline
\end{tabular}

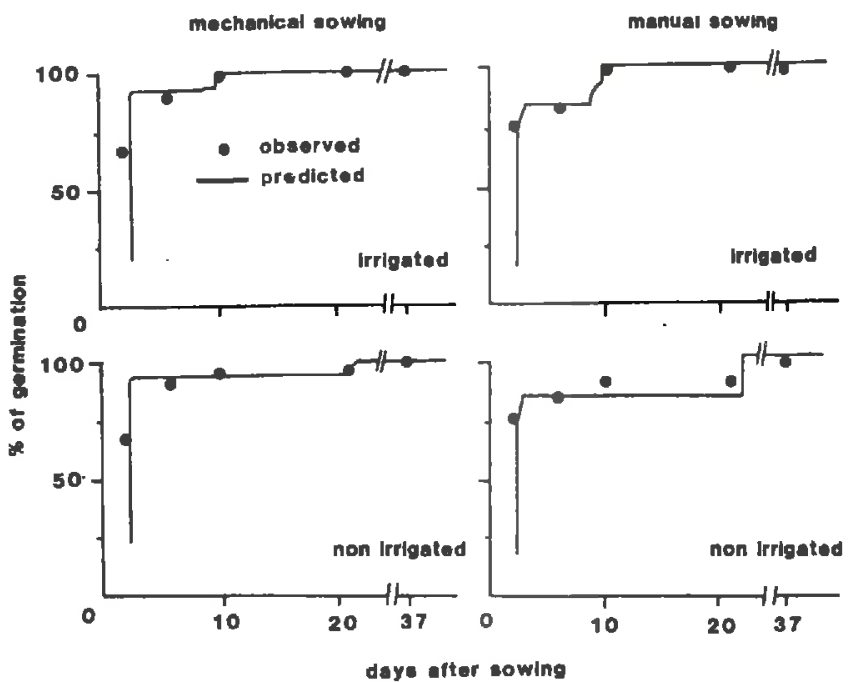

Fig. 15. Measured and predicted germination rates for the irrigated and nonirrigated plots using mechanical or manual sowing techniques.

irrigated and nonirrigated plots and the two sowing techniques. Small differences appeared between the mechanical or manual sowings, because only small differences in soil physical properties were observed from 6 to $12 \mathrm{~cm}$. Furthermore, the total percentage of seeds from 6 to $12 \mathrm{~cm}$ for the manual sowing technique was approximately $20 \%$. The comparison between calculated and observed germination curves was satisfactory for all treatments, suggesting that the proposed model is suitable for estimating wheat seed imbibition and germination processes.

\section{Prediction of Some Typical Cases}

After the previous validation of the model, the proposed approach was used to test the effects of climate and sowing techniques on germination. Various typical climatic sequences for the semi-arid areas were chosen: (i) continuous and moderate rain (the soil water content remains approximately at field capacity); (ii) rain plus drying plus rain (20 mm rain just after sowing, drying for $20 \mathrm{~d}$, and finally $20 \mathrm{~mm}$ rain $21 \mathrm{~d}$ after sowing); (iii) rain plus drying (20 $\mathrm{mm}$ rain just after sowing, and then continuous soil drying). This was done for the manual and mechanical sowing techniques. Results are given in Table 5. First, the sowing techniques caused no differences when climatic conditions were optimal. Second, the duration of germination depended strongly on the position of

Table 5. Predicted germination characteristics for various sowing and climatic conditions.

\begin{tabular}{lccccc}
\hline & & \multicolumn{3}{c}{ Germination } \\
\cline { 5 - 6 } \cline { 5 - 6 } Climate & Sowing & & Start, $\mathbf{h}$ & End, $\mathbf{h}$ & Rate (\%) \\
\hline Rainy & Mechanical & & 48 & 50 & 100 \\
& Manual & & 48 & 56 & 100 \\
Rainy & Mechanical & & 52 & 529 & 100 \\
Dry & & & $(66) \dagger$ & $(98)$ \\
Rainy & Manual & 52 & 529 & 80 \\
& & & $(66)$ & $(72)$ \\
Rainy & Mechanical & 51 & 58 & 84 \\
Dry & Manual & 51 & 58 & 68 \\
\hline
\end{tabular}

† Parentheses indicated the end of the first stage of germination. 
the rainfall events versus time, and different successive germination steps occurred after rewetting of the upper soil layers. Third, the sowing techniques might lead to great differences in the germination rates, particularly under limiting soil moisture conditions. These conclusions agree with some agricultural observations in field and semi-arid conditions (Feneck and Papy, 1977; Bouaziz, 1987).

\section{CONCLUSION}

Imbibition of wheat seeds is very sensitive to soil physical properties, particularly to the soil water potential and seed-soil contact. Seed-soil contact depends upon both the soil structure and water content. The seed-soil contact purtly determines the imbibition rate, whereas the soil water potential affects both the rate of the imbibition process and the possibility of germination, because wheat seeds must reach a critical water content before germination. The proposed model is regarded as satisfactory, provided that preliminary estimates of seed water transfer coefficients in both liquid and vapor phase are obtained. This is true for both controlled laboratory conditions and experimental field conditions. In the latter case, a precise knowledge of seedbed soil structure, water content and seed position is required for the successful application of this approach. This was obtained here by field observations. But it is also possible to use a soil-atmosphere heat and mass transfer model to estimate the water content profiles and soil temperatures before using the proposed model, which requires general climatic conditions, soil thermal and hydrodynamic properties (Sophocleous, 1979; Higuchi, 1984). Finally, the proposed imbibition and germination approach should be regarded as the first stage of a more general model which takes into account the main events from sowing to seedling emergence depending upon soil moisture, soil mechanical impedance and soil surface structure. Thus, its seems reasonable to use such models to optimize agricultural techniques, particularly in areas where variable and extreme climatic conditions are a limiting factor for germination and emergence.

\section{REFERENCES}

Al-Ani, A., J.M. Leblanc, P. Raymond, and A. Pradet. 1982. Effet de la pression partielle d'oxygène sur la vitesse de germination des semences à réserves lipidiques et amylacées: Róle du métabolisme fermentaire. C. R. Acad. Sci. Ser. 2. 295:271-274.

Bard, Y. 1974. Nonlinear parameter estimation. Academic Press, New York.

elongation 1972 . Influence of temperature on germination and elongation on the radicle and shoot on corn (Zea mays L.). Crop Sci. 12:647-650.

Boiffin, J., L. Bruckler, et C. Aubry. 1983. Rôle des propriétés physiques du lit de semences sur l'imbibiton et la germination. III.
Valeur prévisionnelle d'un modèle d'imbibition au champ et caractérisation des lits de semences. Agronomie (Paris)3(4):291-302. Bouaziz, A. 1987. Implantation d'un peuplement de blè tendre en conditions sèches. Analyse physique et modélisation. Thèse de doctorat es Sciences Agronomiques, Institut Agronomique et Vétérinaire Hassan II, Rabat, Maroc.

Bruckler, L. 1983a. Rôle des propriétés physiques du lit de semences sur l'imbibition et la germination. I. Elaboration d'un modèle du systeme 'terre-graine.' Agronomie (Paris) 3(3):213-222.

Bruckler, L. 1983b. Role des proprictes physiques du lit de semences sur l'imbibition el la germination. II. Contrôle expérimental d'un modele d'imbibition des semences et possibilites d'applications. Agronomie (Paris) 3(3):223-232.

Collis-George, N., and J.E. Sands. 1959. The control of seed germination by moisture as a soil physical property. Aust. J. Agric. Res. 10:628-636

Collis-George, N., and J.B. Hector. 1966. Germination of seeds as influenced by matric potential and by area of contact between seed and soil water. Aust. J. Soil Res. 4:145-164.

Come, D. 1970. Les obstacles la germination. Masson et Cie Editeurs, Paris.

Feneck, J., and F, Papy, 1977, Conditiona do roumite de la lovoe en climat mediterraneen. Cas des cultures de certales en sec au Nord du Maroc. Ann. Agron. 28(6):599-635.

Fies, J.C., and P. Stengel. 1981. Densité texturale des sols naturels. 11. Eléments d'interprètation. Agronomie (Paris) 1(8):659-666.

Fleurg, A. 1982. Les problames techniques du semis. Sci. Sol 3:173185 . Hadas, A. 1969. Effects of soil moisture stress on seed germination.
Agron. J. 61:325-327. Hadas, A. 1970. Factors affecting seed germination under soil mois-
ture stress. Isr. J. Agric. Res. 20(1):3-13.

Hadas, A, and E. Stibbe. 1973. An analysis of soil water movement towards seedlings prior to emergence. Ecological studies. Analysis and synthesis, Vol. 4. Springer-Verlag, Berlin, Heidelberg, New York.

Hadas, A., and D. Russo. 1974. Water uptake by seeds as affected by water stress, capillary conductivity, and seed-soil water contact. I. Experimental study. II. Analysis of experimental data. Agron. J. 65:643-652

Hegarty, T.W. 1977 . Seed activation and seed germination under moisture stress. New Phytol. 78:349-359.

Higuchi, M. 1984. Numerical simulation of soil water flow during drying in a non-homogeneous soil. J. of Hydrol. 71:303-334.

Hunter, J.R., and A.E. Erickson. 1952. Relation of seed water tension to soil moisture tension. Agron. J. 44:107-109.

Kaack, K, and K. Kristensen. 1967. Emergence and seedling growth related to oxygen diffusion rate in different soils. Agron. J. 59:541544.

Lindstrom, M.J., R.I. Papendick, and F.E. Koehler. 1976. A model to predict winter wheat emergence as affected by soil temperature, water potential and depth of planting. Agron. J. 68:137-140.

Manohar, M.S., and W. Heydecker. 1964. Effects of water potential on germination of pea seeds. Nature 202:22-24.

Michel, B.E., and M.R. Kaufmann. 1973. The osmotic potential of polyethylen glycol. Plant Physiol. 51:914-916.

Owen, P.C. 1952. The relation of germination of wheat to water potential. J. Exp. Bot. 3(8):188-203.

Papy, F. 1979. Analyse du comportement des cultures de ble dur et d'orge dans differrentes régions céréalières du Maroc à travers leur reaction aux variations interannuelles des regimes pluviométriques. C.R. Acad. Agric. Fr. 3:231-247.

Sedgley, R.H. 1963. The importance of liquid seed contact during germination of Medicago Tribuloides Des. Aust. J. Res. 14:646-

Sophocleous, M. 1979. Analysis of water and heat flow in unsaturated-saturated porous media. Water Resour. Res, 15:1195-1206. Stengel, P. 1979. Utilisation de l'analyse des systèmes de porosité pour la caractérisation de l'état physique du sol in situ. Ann. Agron. 30:27-51. 